\title{
WHAT IS KNOWN ABOUT EMIGRATION OF THE ROMANIAN DOCTORS AND WHAT WE SHOULD EXPECT IN THE FUTURE
}

\author{
MIRELA CRISTINA GEORGESCU ${ }^{1}$, FLORENTINA LIGIA FURTUNESCU ${ }^{2}$, OTILIA \\ FRUMUSACHI $^{3}$, LAVINIA LOPATICA ${ }^{4}$, DANA GALIETA MINCĂ ${ }^{5}$ \\ 1,2,3,4,5 University of Medicine and Pharmacy “Carol Davila” Bucharest
}

Keywords: migration,
Romanian physicians,
retention policy

\begin{abstract}
Romania has experienced in the last two decades a high emigration of the healthcare workforce, especially after joining the European Union. This study aimed to describe the trends in emigration of the Romanian health professionals and the potential changes of the intention to leave, considering the country context and the recent national measures. Four parameters intended to be analyzed: the number of physicians working in Romania, and in other countries respectively, the national capacity for providing undergraduate medical training and the intention to leave of the young graduates. We found an accelerate process of emigration of doctors, especially after the EU accession, wider compared to the increase of the national capacity for providing medical training and more rapid in the last years. The recent measures of motivation through the income increase appear to have limited impact on the intention to leave, at least for the young doctors. Systematic and coordinated efforts are needed in the next future to better understand which are the most effective interventions to respond to this situation. Among these interventions, improving the information system in this area should be a priority.
\end{abstract}

\section{INTRODUCTION}

A well-trained and numerically sufficient workforce was recognized as a key premise in achieving the Agenda 2030 for Sustainable Development, especially the third goal "ensuring healthy lives and promoting well-being for all at all ages (1). Thus, the target $3 \mathrm{c}$ of the Agenda 2030 refers to prioritization of the recruitment, development, training and retention of the health workforce, with focus on least developed countries.

The migration of the medical workforce around the world (including both doctors and nurses) is one of the most important and longest-standing phenomena, associated with socalled medical "brain drain", usually from less developed countries to more prosperous societies (2). The World Health Organization urges the member states to apply ethical recruitment of the health workforce, to support the countries that are experiencing a critical health workforce shortage and to collaborate in information exchange (3).

Romania has experienced in the last two decades a high emigration of the healthcare workforce, especially after joining the European Union (EU) in January 2007 (4-6). Among the most common reasons for leaving the country, low salaries, controversial social status, limited career development opportunities, and discrepancies between the level of competencies required and the working conditions appeared to be most incriminated (4). Beyond these, once started the preparation for EU accession, the EU legislative framework was implemented in national legislation and, consequently, the mutual recognition of diplomas encouraged the health professionals to find opportunities for working in EU member states which are more developed (5). The phenomenon was recognized and prioritized on the political agenda, but the reforming measures for retaining the health workforce were rather weak around the accession and in the decade after $(4,7,8)$.
The National Health Strategy 2014 - 2020, a commitment made by the government with the intention to better plan and use the EU funds, stipulates among its objectives to implement a sustainable policy for ensuring sufficient human resources for health (9). Main directions envisaged in this purpose are to put in place a flexible legislative framework, allowing to incentivize the health staff working in most deprived areas and to develop the training capacity (initial and continuous medical education)

In line with the strategy objectives, in 2017 a new salary law has been promoted, including a very stimulative measure for the health workforce, to increase immediately the salaries of doctors and nurses working in the public sector, to the forecasted level for year 2023 (10). This increase was very consistent for an average salary and it entered into force in March 2018. In this context there was expected to provide enough motivation for the Romanian doctors and nurses to remain and work in the country or, eventually to come back in the country for those working abroad.

\section{PURPOSE}

In our study we aimed to describe the trends in emigration of the Romanian health professionals and the potential changes of the intention to leave, considering the country context and the recent national measures meant to stimulate the retention of the health workforce in Romania.

\section{MATERIALS AND METHODS}

For this purpose, we did a critical appraisal of published literature (including grey reports) and we investigated the official sources of routine reported data concerning health workforce (national and international databases).

Among the different categories of health

${ }^{1}$ Corresponding author: Mirela Cristina Georgescu, Str. Leonte Anastasievici Nr. 1-3, Camera 224, Bucureşti, România, E-mail: mirela.gerogescu@umfcd.ro, Phone: +0723 537913

Article received on 20.06.2020 and accepted for publication on 24.08.2020 


\section{PUBLIC HEALTH AND MANAGEMENT}

professionals, we focused in this paper only on physicians (all specialties, excluding dentists).

We analyzed four parameters:

a. The number of physicians working in Romania

b. The number of physicians trained in Romania and working in other countries

c. The capacity for undergraduate medical training in the country

d. The intention to leave of the young graduates.

For analyzing the number of health professionals working in Romania we used the data reported by the National Institute for Statistics for the interval 1997 - 2019. We investigated the absolute numbers per year and the annual percentage change compared to baseline (1997). For analyzing the number of physicians trained in Romania and working country we were not able to identify reliable national data. The professional organization (Romanian College of Physicians) and the Ministry of Health do communicate the number of physician requiring documentation for working abroad, but not the number of doctors leaving the country. This fact was mentioned by other studies and did not change in the last years $(4,7)$. Thus, we used the Organisation for Economic Cooperation and Development (OECD) database - Foreign trained doctors by country of origin, reported by 25 OECD countries. Data are available since the year 2000 and we analyzed the interval 2000 - 2017 (last available complete reporting). We analyzed the trend of the total number and the most preferred countries for emigration.

The capacity for undergraduate medical training in the country was analyzed based on the Eurostat indicator "health graduates - medical doctors".For investigating the intention to leave for the young professionals we ellaborated a questionnaire with three sections concerning personal data, specialties of interest for residency and intention to leave. We applied this questionnaire to the students graduating the medicine programs in three consecutive years $(2016-2018)$ at the largest university of medicine from Romania. We collected quantitative and qualitative variables. The quantitative ones were analyzed as average/median and standard deviations and the qualitative ones as proportions respectively.

\section{RESULTS}

During the study interval, the number of physicians practicing in Romania increased with about a half, and this ascendant trend was constant over the years, with a small decline around the year of the EU accession (2007) and a more ascendant slope in the last two-three years, possibly due to the effort to increase the physicians' salary in the public sector (Fig. $1)$.

Figure no. 1. Trend of Romanian physicians working in Romania during 1997 - 2019 (absolute number and \% versus baseline)

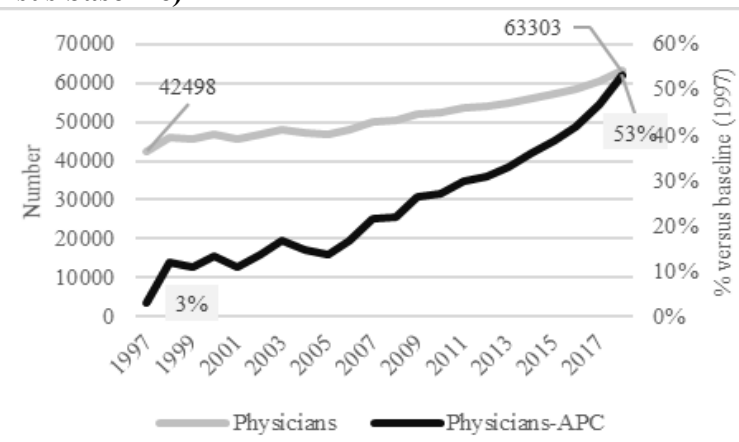

Data source: The National Institute of Statistics Database (11)

Based on this situation, we could assume that coverage with physician for the Romanian population improved in the last two decades. Still, many sources suggest that the distribution of the physicians is unequal among regions and counties, but especially among rural and urban areas, with high figures in the big cities/university centres and very low coverage in rural and deprived areas $(4,7)$. The analysis of the stock of foreign doctors trained in Romania and working in other countries (available for 25 OECD countries) revealed a much serious increase from the year 2000 (first available for this indicator) (12). Thus, in year 2000, about 2000 doctors trained in Romania used to work in the OECD reporting countries, but in 2017 this number raised ten times, to over 20000 (12) (Fig. 2)

Figure no. 2. Physicians trained in Romania and working abroad - number and change versus year 2000

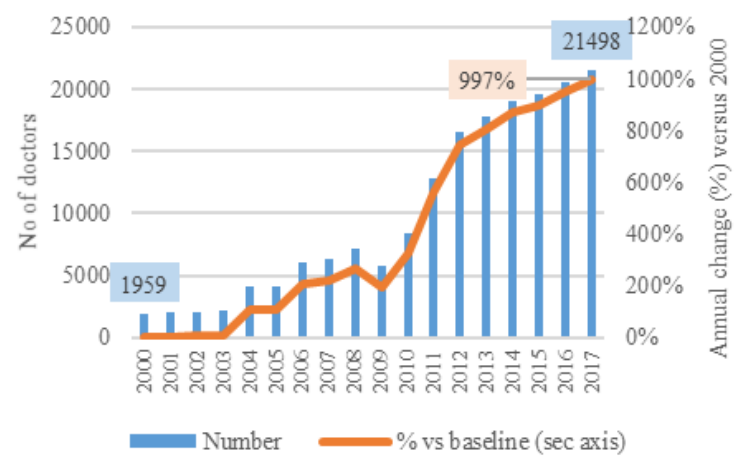

Data source: Organisation for Economic Cooperation and Development (12)

In 2000 , most preferred countries seemed to be Israel (with 1260 Romanian doctors), Germany, Sweden and Canada (342, 188 and 164 Romanian doctors respectively), with the specification that reporting from United States of America (one of most important attractions) missed for that year (12).

Situation changed radically in the next decades, when EU countries took the lead in the preferences of the Romanian doctors (Fig. 3)

Figure no. 3. Number of physiciand trained in Romania and working in different countries 2008 and 2017

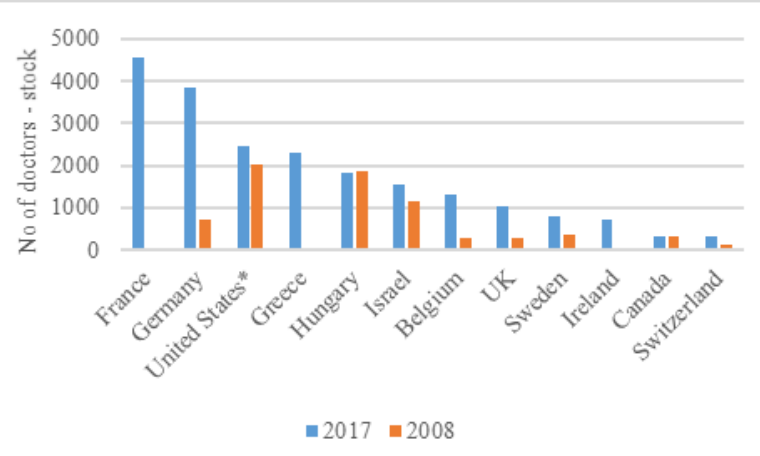

Data source: The Organization for Economic Cooperation and Development (12)

However, data from last two figures should be interpreted with caution because Italy and Spain did not report this indicator to OECD, but evidence suggests they play important places among the Romanian nurses, but also doctors' preferences $(7,13)$. The national capacity for medical training increased by $45 \%$ during the last decades, from 3515 graduates in 1997 to 5076 in 2018 respectively (14).

The intention to leave of the young Romanian doctors was suggested by some publications $(5,7,15)$. We tried to investigate this parameter in three consecutive cohorts of graduates of the largest faculty of medicine from the country. Meanwhile, in 2017 a new law stipulated a consistent increase of the salaries for doctors and nurses from the public sector, and 


\section{PUBLIC HEALTH AND MANAGEMENT}

the measure was applied starting from March 2018. We assumed that salaries increase will reduce the graduates' intention to leave the country for a specialization abroad. We got answers from more than 2000 respondents $(778,799$ and 736 graduates in 2016, 2017 and 2018 respectively). The characteristics of the respondents were similar and the intention to leave was expressed by $18 \%$ of the graduates, without significant differences among the cohorts $\left(\mathrm{p}=0.872\right.$, Test $\left.\mathrm{Chi}^{2}\right)$.

\section{DISCUSSIONS}

Our study revealed that Romania faced an increasing loss of doctors in the last two decades, through emigration, but meanwhile an increase of the number of doctors working in the country and also an expansion of the national capacity for medical training. The increase of the emigration appears to have a more rapid rhythm compared to national capacity for training and national increase of the number of doctors. Thus, in 2000, the number of doctors working abroad represented $60 \%$ from the training capacity for one year, and the number of doctors working in the country reached to 14 cohorts of graduates $(1400 \%$ from national capacity for one year). In 2008, first year after EU accession, the number of doctors working abroad increased by $266 \%$ compared to year 2000 , but the training capacity decreased and the doctors working domestically ncreased only by $10 \%$ and the situation became more discrepant in 2017 (Table 1)

Table no. 1. Synthesis of parameters indicating the coverage with doctors in Romania in relevant years

\begin{tabular}{|c|c|c|c|c|}
\hline Year & Parameter & $\begin{array}{l}\text { Doctors working } \\
\text { in the country }\end{array}$ & $\begin{array}{l}\text { Training } \\
\text { capacity }\end{array}$ & $\begin{array}{l}\text { Doctors } \\
\text { working } \\
\text { abroad }\end{array}$ \\
\hline 2000 & Number & 45786 & 3276 & 1959 \\
\hline 2001 & \multirow{3}{*}{ 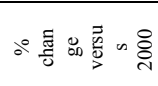 } & $2 \%$ & $6 \%$ & $3 \%$ \\
\hline 2008 & & $10 \%$ & $-22 \%$ & $266 \%$ \\
\hline 2017 & & $28 \%$ & $41 \%$ & $997 \%$ \\
\hline
\end{tabular}

Beyond this alarming data, we should note that the Romanian authorities tried to respond to this situation, by adopting few important measures among which: the approval of the national strategy for health, including objectives related to sustainable human resources, the significant increase in salaries for medical staff working in public medical units, the increase of the medical training capacity. However, these measures, and in particular the salary raising, seem to have limited influence in decreasing the trend of migration, at least up to present years. There is a possibility to notice a decline in the interest for leaving the country in the coming years.

The present analysis revealed however a considerably more reduce intention to leave among the young doctors, compared to previous researches in different populations of Romanian student and at different time, according to which $85 \%$ of the students intended to leave the country (15).

Our study has important limitations related to the weakness of the national information system in registering the movement of the medical doctors. Another limitation is related to the fact that we focused on doctors, but nurses represents an important part of the model. Last but not least, we based our findings about doctors' emigration only on data reported by other countries in an international database, but not on national data, which should be developed in the future.

\section{CONCLUSIONS}

We found in our study an accelerate process of emigration of doctors, especially after the EU accession (2007). This process is wider compared to the increase of the national capacity for providing medical training and more accelerated in the last years. The recent measures of motivation through the income increase appear to have limited impact on the intention to leave, at least for the young doctors. Systematic and coordinated efforts are needed in the next future to better understand which are the most effective interventions to respond to this situation. Among these interventions, improving the information system in this area should be a priority.

\section{REFERENCES}

1. United Nations. Resolution A/RES/70/1. Transforming our world: The 2030 Agenda for Sustainable Development. Adopted 21 October 2015

2. Rutten, Martine M., The Economic Impact of Medical Migration: A Receiving Country's Perspective. Review of International Economics. 2009; 17(1):156-171. Available at SSRN: $\quad$ https://ssrn.com/abstract $=1395448 \quad$ or http://dx.doi.org/10.1111/j.1467-9396.2008.00798.x

3. World Health Organization. The WHO Global Code of Practice of the International Recruitment of the Health Personnel. Geneva: WHO; 2010.

4. Galan A, Olsavsky V, Vladescu C. Emergent challenge of health professional emigration: Romania's accession to the EU. In: Wismar M, Maier C, Glinos I, Dussault G, Figueras $\mathrm{J}$, editors. Health professionals mobility and health systems: evidence from 17 European countries. Brussels: European Observatory on Health Systems and Policies; 2011.

5. Glinos IA. Health professional mobility in the European Union: Exploring the equity and efficiency of free movement. Health Policy.2015; 119:1529-36. Available from:

https://www.sciencedirect.com/science/article/pii/S016885 1015002146

6. Rohova M. Health Professionals Migration - The case of Romania. Journal of Health Economics and Management. 2011; 2(40):3-21. Available from: https://www.researchgate.net/publication/267210017_Healt h_Professionals_Migration_- the Case of Romania

7. Paina $L$ et al. Implementing the Code of Practice on International Recruitment in Romania - exploring the current state of implementation and what Romania is doing to retain its domestic health workforce. Human Resources for Health. 2016;14(Suppl 1):22 DOI 10.1186/s12960-0160119-6

8. Mariana Balan \& Brindusa Mihaela Radu. New Trends Of Health Worker Migration. Case Of Romania. Annals Economy Series, Constantin Brancusi University, Faculty of Economics. 2019 June;3:5-14. Available from: https://ideas.repec.org/a/cbu/jrnlec/y2019v3p5-14.html

9. The Government Decision n. 1028/2014 for approving the National Health Strategy 2014-2020 and its Action Plan for implementation

10. The Law regarding the salaries of the budgetary personnel no $153 / 2017$ with subsequent amendments.

11. National Institute for Statistics Database Tempo-on line. Available from:

12. OECD Database. Available from:

13. OECD. Recent Trends in International Migration of Doctors, Nurses and Medical Students, OECD Publishing, Paris. 2019. Available from: https://doi.org/10.1787/5571 ef48-en.

14. Eurostat Database - Health graduates. Available from: https://appsso.eurostat.ec.europa.eu

15. Suciu, Ş.M., Popescu, C.A., Ciumageanu, M.D. et al. Physician migration at its roots: a study on the emigration preferences and plans among medical students in Romania. Hum Resour Health 15, 6 (2017). https://doi.org/10.1186/s12960-017-0181-8: 